\title{
O CINEMA COMO FORMAÇÃO: A ESCOLA COMO MEDIADORA DA RELAÇÃO ENTRE JOVENS E FILMESi
}

\author{
CINEMA AS TRAINING: SCHOOL AS MEDIATOR OF THE \\ RELATION BETWEEN YOUNG PEOPLE AND FILMS
EL CINE COMO FORMACIÓN: LA ESCUELA COMO MEDIADORA DE LAS RELACIÓN ENTRE JOVÉNES Y PELÍCULAS

\begin{abstract}
Adriana Hoffmann Fernandes ${ }^{1}$
Pedro Benjamin Garcia ${ }^{2}$

RESUMO

O artigo aborda os "achados" de uma pesquisa com cinema na escola, com jovens do ensino médio integrado, de uma escola de formação técnica. O campo de pesquisa foi constituído pelas rodas de leitura, com exibições, debates e leituras associadas aos filmes exibidos para as turmas, num processo de cooperação científica entre duas universidades e a escola de ensino médio e a colaboração estreita dos professores da escola. A pesquisa apontou que as rodas de leitura trouxeram aspectos amplos de formação com o cinema, experimentados pelos jovens na escola. Essas práticas apontam os processos formativos vividos ao longo do curso, fazendo-nos refletir sobre o papel mediador da escola na relação entre cinema e juventude. A escola aparece como sensibilizadora, desautomatizadora do olhar, algo que nos surpreendeu e confirmou o que discutem pesquisadores da área, como Dussel (2014), quando afirma que o cinema na escola nem sempre faz desse espaço pedagógico algo empobrecedor. Em diálogo com estudiosos de cinema e educação, destacamos como o processo vivido na escola pesquisada aponta para uma relação com o cinema como formação.
\end{abstract}

PALAVRAS-CHAVE: Cinema. Jovens. Formação. Escola.

\begin{abstract}
This paper addresses the "findings" of a research related to cinema at school with integrated high school students from a technical training school. The fieldwork took place at reading groups with film screenings, debates and readings associated with the films in a process of scientific cooperation between two universities and the high school with close collaboration of teachers. The results pointed out that the reading groups brought up the broad aspects of education and cinema lived by young people at school. They indicate that the group practices highlighted formative processes, making us reflect on the mediating role of school in the relation between cinema and young people. Hence, the school sensitizes and de-automatizes the look, something that surprised us and suggested, as researchers as Dussel (2014) in the field state, that approaching cinema at school is not always pedagogically detrimental as some critics argue. Based on the studies of cinema and education scholars, we point out to how the results of this research indicate that cinema can be linked to education.
\end{abstract}

KEYWORDS: Cinema. Young people. Education. School.

\footnotetext{
${ }^{1}$ Doutora em Educação e Mídia - Universidade Federal do Estado do Rio de Janeiro (UFRJ) - Rio de Janeiro, RJ Brasil. Professora adjunta no PPGEDU e Escola de Educação na Universidade Federal do Estado do Rio de Janeiro (UNIRIO) - Rio de Janeiro, RJ - Brasil. E-mail: hoffadri58@gmail.com

${ }^{2}$ Doutor em Antropologia Social - Universidade Federal do Rio de Janeiro, Professor adjunto na Universidade Católica de Petrópolis (UCP) - Petrópolis, RJ. E-mail: benjamimgarcia@gmail.com
}

Submetido em: 21/11/2016 - Aceito em: 28/02/2017
(C) ETD-Educação Temática Digital
Campinas, SP
v.19
n. 2
p. 384-399
abr./jun. 2017 


\title{
RESUMEN
}

El artículo aborda los "hallados" de una investigación con cine en la escuela con jóvenes de la enseñanza media integrada ("ensino médio integrado", en Brasil) de una escuela de formación técnica. El campo de investigación se dio en círculos de lectura con exhibiciones, debates y lecturas asociadas a las películas exhibidas para las clases en un proceso de cooperación científica entre dos universidades y la escuela de enseñanza media con la estrecha colaboración de los profesores de la escuela. La investigación señaló que los círculos de lectura trajeron los aspectos amplios de la formación con el cine vividos por los jóvenes en la escuela. En las prácticas vividas por los jóvenes en la escuela, ellos apuntan los procesos formativos vividos a lo largo del curso, lo que nos hace reflexionar sobre el papel mediador de la escuela en la relación que se establece entre cine y juventud. La escuela aparece como sensibilizadora, desautomatizadora del mirar, algo que nos sorprendió y confirmó lo que discuten los investigadores como Dussel (2014), cuando afirman que el cine en la escuela no siempre hace de ese espacio pedagógico algo empobrecedor. En diálogo con los estudiosos del cine y de la educación, señalamos como el proceso vivido en esa escuela investigada apunta para una relación con el cine como formación.

PALABRAS CLAVE: Cine. Jóvenes. Formación. Escuela.

\begin{abstract}
A primeira sessão de cinema nos moldes em que a conhecemos hoje, ou seja, numa sala pública de projeções, aconteceu há mais de dois mil anos, muito antes que Loius Lumière mostrasse as paisagens animadas de La ciutat no Grand Café de Paris. Ela teve lugar na imaginação de Platão (...) e veio a ser conhecida posteriormente como "alegoria da caverna". Ela inaugura também na história do pensamento ocidental, o horror à razão dos sentidos, o escárnio às funções do prazer, a repulsa a todas as construções gratuitas do imaginário, a negação, enfim, de tudo isso que, dois milênios depois, seria a substância de uma arte que paradoxalmente, o próprio Platão inventava. Tudo, é claro, em nome de um compromisso sem tréguas com o conhecimento (...), o conhecimento que transcende as determinações imediatas e voa em busca das essências. Arlindo Machado
\end{abstract}

Nossa relação com a visualidade não é algo recente como aponta essa citação de Arlindo Machado (2007, p.54). Desde que nos conhecemos, pensamos e inventamos imagens que contam histórias, geramos conhecimento a partir de imagens como a alegoria da caverna de Platão. No entanto, nossa relação com as imagens vem mudando ao longo do tempo.

Dussel (2014) analisa que, no final do século XIX e início do século XX, os sujeitos da escola e do cinema eram, sobretudo, visuais: espectadores, criadores de imagens, usuários e leitores de tecnologias portadoras de visualidade. A visualidade não é uma embalagem para outros conteúdos, mas é ela mesma a organização de relações e subjetividades. Ela organiza o sensível, o belo, o digno de atenção, induz formas de olhar e de mostrar, promove certas visibilidades e relega outras. A visibilidade tem uma história, uma pedagogia: há que se conhecer como olhar reflexivamente, como se distanciar, como se converter em espectador.

\section{(C) ETD-Educação Temática Digital Campinas, SP v.19 $\quad$ n.2 $\quad$ p. 384-399 abr./jun. 2017}


Sabemos que, nas sociedades contemporâneas, os sentidos se organizam cada vez mais a partir de imagens, que exercem papel de mediadoras entre o sujeito e a cultura. A imagem audiovisual não só assegura formas de socialização e transmissão de informações, mas também faz parte da nossa prática social e cultural, das nossas formas de ver e ler o que acontece à nossa volta. Estamos vivendo uma audiovisualização da cultura. As crianças e os jovens vivem, de forma cada vez mais intensa, uma relação com o conhecimento vinculada à imagem em seu processo de formação.

A escola não está fora desse contexto. Dussel (2014) lembra que, desde o século XIX, circula um discurso pedagógico do valor das imagens como aquelas que ajudam a aprender mais rápido. Esse discurso pode ser percebido até os dias atuais, embora tais afirmações possam ser questionadas. Assim como apareceu em nossa pesquisa, aparece na de Dussel, a prática dos jovens que apontam ver cinema pelo Youtube ou outros sites como Netflix. Temos que considerar que a experiência do cinema hoje é, como diz a autora, apenas uma parte do que hoje representa a imagem em movimento. São diferentes e variados os modos de apropriação das imagens vividos pelos jovens na atualidade, diante da multiplicidade de usos e plataformas. Mesmo sabendo disso, este artigo se centra apenas no cinema na grande tela, parte da pesquisa aqui relatada.

Assim como Serra (2006), trazemos algumas questões que abrem esse debate das relações entre o cinema e a escola: O que significa para a escola abrir as portas ao cinema? Qual é o objetivo do cinema na escola? Que tipo de experiência propõe? O cinema constitui uma experiência pedagógica?

Neste artigo, pretendemos mostrar como ocorreu a pesquisa com o cinema numa escola, para apresentar uma proposta de relação entre cinema e escola, em que a escola seja mediadora entre os jovens e as imagens. Ao dialogar com Serra (2006), consideramos também - assim como a autora - que a experiência do cinema é semelhante a da leitura, e que pensar cinema na escola é pensar uma experiência da ordem da formação. Por isso também, nesta pesquisa, sempre associamos os filmes a textos e realizamos os debates em rodas de leitura, compreendendo a leitura de filmes em associação com a de textos.

Além das rodas, foram realizadas entrevistas e conversas informais, registradas nos diários de campo da pesquisa. Algumas questões que transparecem neste artigo são: $O$ que aprendem os jovens quando se propõe a trabalhar com o cinema na escola? Afinal, como o cinema faz parte da formação dos jovens na escola? O objetivo de trabalhar o cinema na

\section{(c) ETD-Educação Temática Digital Campinas, SP v.19 $\quad$ n.2 $\quad$ p. 384-399 abr./jun. 2017}


escola é pensá-lo como leitura, como ampliação de sentidos possíveis. É importante destacar que a escola em que foi realizada a pesquisa tem um currículo de formação técnica e um trabalho todo voltado para o audiovisual, trabalhando com exibições, debates de filmes e reflexões sobre o fazer cinema. Portanto, a nossa pesquisa teve como tarefa dialogar nas rodas e olhar mais de perto para as práticas que já aconteciam na escola.

Este artigo aborda a sistematização de aspectos que sobressaíram na pesquisa realizada dentro de uma instituição escolar estadual da região serrana, com turmas de Ensino Médio Integrado (EMI), em Formação de Técnico Audiovisual. Analisaram-se observações e reflexões com jovens na faixa etária de 14 a 17 anos, no período de 20102013, na cooperação científica entre programas de pós-graduação de duas universidades localizados no estado do Rio de Janeiro. Os dois projetos tiveram em comum o foco no cinema como um modo de leitura e formação de jovens, tendo essa escola como um dos campos de pesquisa.

Selecionamos, do material recolhido, algumas falas que dizem respeito ao processo de formação dos jovens pesquisados, dialogando com autores que nos fazem pensar sobre esse processo vivido com o cinema, como Duarte e Alegria (2008), Xavier (2008), Carrière (1995) entre outros. Os diálogos que mantivemos durante a pesquisa mostraram a relação entre o cinema e a escola e vida pessoal de cada um deles.

\section{"FILMES DIFERENTES" - "TEM QUE RACIOCINAR MUITO PARA ENTENDER..."}

O primeiro olhar, "é ou não é". O raciocínio vem depois (para aprovar nosso primeiro olhar). Tirar as coisas do hábito, descloroformizá-las. Robert Bresson

Olhar primeiro. Raciocinar depois. Isso é o que nos diz Bresson (2005), ao pensar suas notas. Tirar as coisas do hábito. Ver diferentes, descloroformizando-as. Essas frases de Bresson nos ajudam pensar sobre o que apontaram os jovens na pesquisa. Parece-nos que o que eles fizeram foi isso: olhar, raciocinar, tirar do hábito.

Os filmes 'diferentes', segundo eles, são os que fogem de uma proposta do cinema americano em sua forma estereotipada: sexo, ação, violência. Os que, segundo Bresson, os tiram do hábito de ver sempre mais do mesmo. Esses filmes são ditos por eles como 'diferentes, por provocarem outros pensares e outras relações. Nesse aprendizado da exibição e reflexão sobre filmes na escola, esses jovens passam a ter uma outra percepção

CC ETD-Educação Temática Digital Campinas, SP $\quad$ v.19 $\quad$ n.2 $\quad$ p. 384-399 abr./jun. 2017 
do fazer cinematográfico. Algo análogo ao que nos fala Pasolini (apud SAVERNINI, 2004, p. 30), ao explicitar os efeitos que produzem determinados procedimentos técnicos: "[...] o emprego pródigo do zoom, com suas objetivas muito alongadas, que se colam às coisas, dilatando-se como se fossem pães levedados em excesso, os contraluzes contínuos e fingidamente acidentais [...] os travellings exasperantes, as montagens falseadas..."

É o que transparece no diálogo a seguir:

Marina: Eu acho que é muito bom, no sentido de que a gente não conhece somente aquela cultura americana de filme que é só feito para vender. E esses filmes diferentes, na verdade, estão com o objetivo de passar uma mensagem diferente daqueles filmes de ação que você só vê coisa explodir... De acordo com o tempo, eu aprendi a gostar de filmes assim, porque são filmes que não são muito divulgados... São filmes lentos, que não têm aquele pique de filme americano, mas que são filmes...

Carlos: essa questão de filmes antigos, mas com uma linguagem que vem até os dias de hoje... Lembrou-me um filme que a gente foi ver lá na UCP, numa mostra de cinema e filosofia. Foi o filme 2001: uma odisseia no espaço... Ele trata muito isso... Ele faz essa questão de... É um filme... Eu até falei com o rapaz que tava lá administrando: "poxa, é um filme tão antigo, mas que fala de coisas que estão acontecendo hoje...foi filmado lá em 1900 e bolinha..." (grifos nossos)

Mesmo elogiando a opção por filmes 'diferentes', em geral mais antigos, eles não rejeitam os contemporâneos 'que interessem os jovens' como disse outra jovem. Em alguns casos, como diz uma das jovens, um filme "totalmente louco. Se você não tiver muita cabeça, você não consegue entender... é um filme longo, é um filme que tem que raciocinar muito para entender... e as pessoas não querem isso, as pessoas hoje querem ver a mulher que trai o marido..."

O que os jovens dizem relaciona-se com o que Ismail Xavier afirma, em entrevista concedida à Revista Educação e Realidade:

O cinema que "educa" é o cinema que faz pensar, não só o cinema, mas as mais variadas experiências e questões que coloca em foco. Ou seja, a questão não é "passar conteúdos", mas provocar a reflexão, questionar o que, sendo um constructo que tem história, é tomado como natureza, dado inquestionável. (XAVIER, 2008, p. 15)

O cinema, em muitos casos, amplia as possibilidades de leitura, permitindo a problematização de diferentes questões sob novos pontos de vista. Os 'filmes diferentes', como nomeados por eles, são, em certa medida, filmes que fazem pensar, que os obrigam a raciocinar, que os fazem tirar do hábito o olhar. Duarte e Alegria

\section{(C) ETD-Educação Temática Digital Campinas, SP v.19 $\quad$ n.2 $\quad$ p.384-399 abr./jun. 2017}


(2008) reiteram esse olhar, ao comentar que, assim como o contato com boas obras literárias é um aspecto essencial para a formação, o mesmo pode ocorrer em relação ao cinema: "o contato com bons filmes altera o modo de ver e contribui para o desenvolvimento da capacidade de julgamento estético de obras cinematográficas e, por extensão, da produção audiovisual" (p. 74).

Xavier (2008) afirma que os "filmes que fazem pensar" não são acessíveis apenas aos especialistas. Os filmes que os alunos/as do EMI nomeiam como "diferentes" são aqueles em que, dizem, é necessário refletir mais intensamente para participarem dos debates. 0 repertório que vão construindo na escola provoca neles uma mudança que contribui para a criação das suas narrativas audiovisuais, conforme aponta Xavier:

\begin{abstract}
Para mim, o que vale - estética, cultural e politicamente - é a relação com a imagem (e a narrativa) que não compõe de imediato a certeza sobre este "do que se trata" e lança o desafio para explorar terrenos não, codificados da experiência. Tanto melhor se o próprio filme se estrutura para impedir o conforto de reconhecimento do mesmo, de confirmação do que se supõe saber. O modernismo nos legou este imperativo de desautomatização da percepção e de ampliação de repertório como tarefa da arte, recuperação de uma sensibilidade amortecida pelo investimento prático, em que o cotidiano se faz o lugar do hábito, da percepção que está instrumentada por uma interação com o mundo marcada pelo cumprimento de certas finalidades, das mesmas finalidades a cada novo dia. Nesse terreno, seria ilusório supor que a relação produtiva e enriquecedora com as imagens e narrativas desconcertantes se apoie na força exclusiva de um saber das formas e de um repertório analítico que nos capacite a uma recepção "adequada", pois aqui, como em outros terrenos, quase tudo depende da postura, de uma disponibilidade, de uma forma de interagir com as imagens (e narrativas), que têm a ver com todas as dimensões da nossa formação pessoal e inserção social. (XAVIER, 2008, p.17. grifos nossos)
\end{abstract}

Essa desautomatização da percepção, ampliação do repertório, recuperação da sensibilidade, trazendo novas formas de interagir com as imagens como fazendo parte da formação pessoal e social do sujeito, é o que aparentemente esses jovens parecem nos dizer que vivem nas práticas com o cinema na escola, nas quais a roda de leitura é somente mais uma delas. Explorar terrenos não codificados da experiência de "ver filmes diferentes" parece ser parte desse processo de formação.

\title{
(C) ETD-Educação Temática Digital Campinas, SP v.19 $\quad$ n.2 $\quad$ p. 384-399 abr./jun. 2017
}




\section{"SÓ REPARA QUEM TEM AQUELA PRÁTICA" - O APRENDIZADO COLETIVO CONSTITUTIVO DO VER EM COMUNIDADE}

Imagens e sons são como pessoas que se encontram ao longo de um caminho e não podem mais se separar. Robert Bresson

Esta citação se refere a essa combinação entre imagens e pessoas, que aprendem a ver juntas, em comunidade, como transpareceu nesta pesquisa. Aprender a ver junto parece ser também parte desse processo vivido na escola.

Cordeiro (2012), em pesquisa de mestrado, realizada nesse mesmo local, na parceria que realizamos entre universidade e escola, aponta, como dimensão da relação dos jovens com o cinema, a questão do 'assistir com quem tem um mesmo aprendizado'. Nesse sentido, Jane afirma ${ }^{3}$ :

Eu já me dei mal por causa disso, porque eu já tentei ver filme com alguém que não entende do que a gente tá falando. E eu sou o tipo de pessoa que, quando eu aprendo alguma coisa, eu fico naquilo o tempo inteiro, então, eu vejo um filme e fico: "Caraca, ângulo aberto, ângulo não sei o quê...", aí a pessoa pergunta: “O que você tá falando?", e eu: "Não, nada não, um negócio aí." Eu tentei ver filme com o meu namorado, mas não deu. Ele desistiu de ver filme comigo, porque eu falava mais dos ângulos que da própria história do filme, e o final do filme eu não gostei, podia ter terminado de outro jeito. E ele: "Ah, eu gostei do filme, eu não reparei em nada, não." "É claro que você não reparou em nada", eu disse," só repara quem tem aquela prática". (2008, p.16. grifos nossos)

Os jovens, pela vivência na escola, acabam fazendo parte de uma comunidade interpretativa que os faz afirmar: 'só entende quem tem aquela prática'. O fato de compartilharem um mesmo processo de aprendizagem permite-lhes fazer leituras semelhantes e partilhadas, próprias desse grupo "com a mesma prática".

Entende-se, por comunidade interpretativa, de acordo com Varella (1999), "os sujeitos que se agrupam compartilhando regras e estratégias de leitura, que fixam uma aceitabilidade interpretativa permitindo a fluência na comunicação" (p. 12). Os "que não têm a mesma prática" não compartilham os mesmos significados. A comunidade interpretativa, como parte da constituição da relação dos sujeitos com os produtos culturais, é discutida em várias pesquisas com mídias, como a de Fernandes e Silva (2005) e Fernandes (2012), embora uma tenha sido com leitura de quadrinhos e a outra com TV.

\footnotetext{
${ }^{3}$ Optamos por utilizar nomes fictícios para os jovens participantes da pesquisa.

(C) ETD-Educação Temática Digital Campinas, SP v.19 $\quad$ n.2 $\quad$ p. 384-399 abr./jun. 2017
} 
Participar de uma comunidade que compartilha significados e valores a respeito de determinados filmes constitui os jovens pesquisados como "alunos do EMI" e cria uma identidade valorizada por eles e pelos demais alunos da escola. Mas o que nessa comunidade definem como "um bom filme"? Como se apropriam de um filme com essa qualificação? Entendemos que os eixos a seguir, que abordam esses aspectos da produção de filmes, estão também intrinsecamente relacionados ao modo como assistem e debatem os filmes nesse contexto formativo.

\title{
COMO UM CINECLUBE - "A GENTE NÃO SÓ VIU O FILME, MAS FOI ANALISANDO, SABENDO QUE IA TER UMA DISCUSSÃO DEPOIS..."
}

Tenha o olho do pintor. O pintor cria olhando. Robert Bresson

Os filmes que se olha com o olho de um pintor, o olho de criação que permite analisar, criar ao ver são parte desse processo de formação. Nas conversas com os jovens sobre o que seria um bom filme, transparece esse olhar da criação.

\begin{abstract}
Entrevistadora: - Vocês acham que algum filme tem que ter fórmula para dar certo? Felipe: - Acho que tem que ter um bom significado e um bom começo de história assim, bom princípio, bom, pra quê que eu tô querendo fazer aquele filme ali, se for fazer um filme só por fazer, acho que não fica legal, não...

Jéssica: - Acho que a fórmula seria um roteiro, o roteiro muito bem construído. Tem que passar pro papel pra se organizar...

Entrevistadora: - E vocês acham que as escolhas dos autores, as músicas que vão ser passadas no filme também influenciam pra que seja um bom filme?

Jéssica: - ... Até porque, tipo assim, a música, acho que ela cria um clima assim, um ambiente, então ela mexe com a emoção da pessoa, entende?(...) se bota uma música (lenta), "pô" você sabe que é uma coisa mais romântica, mais envolvente... Felipe: - A música te leva ao contexto do filme, te leva ao clímax.
\end{abstract}

Milena: - A iluminação, as cores do filme também te dá, tipo, se a imagem for ruim, você não vai querer assistir, você vai ter tanta dificuldade para entender, assim, o filme antigo, a gente não gosta por causa da imagem. [Risos] (grifos nossos)

Os jovens apontam, nesse diálogo, o que para eles tem que ter um bom filme: uma boa história, um bom roteiro, a música oportuna, a correta iluminação; boa fotografia ou boas imagens, ou seja, discutem o 'formato' do filme. Esses diferentes elementos aparecem em suas falas. Qualificam o bom filme pelo entendimento e aprendizagem que estão

\section{(C) ETD-Educação Temática Digital Campinas, SP v.19 n.2 $\quad$ p. 384-399 abr./jun. 2017}


realizando acerca de sua linguagem. Mas também falam de perspectivas pessoais ao dizerem que "não gostam de filmes antigos por causa da imagem".

O fato de assistirem e debaterem filmes, tanto nas rodas de leitura quanto nas demais atividades da escola, institui um ambiente de cineclube (mesmo sem usar esse nome), que gera discussões e debates que não surgiriam, se essa 'comunidade' não tivesse em seu repertório de leitura 'filmes diferentes'.

Em Adeus, Lênin! (2003), filme de Wolfgang Becker, que se passa em Berlim Oriental, no período em que um muro dividia as duas Alemanhas, uma educadora da Alemanha Oriental se choca com a visão do seu filho participando de uma manifestação de rua contra o regime e sofre um ataque cardíaco. Desacordada durante cerca de dez meses, não tem conhecimento das transformações que ocorreram no país com a reunificação das duas Alemanhas. Temendo que a sua mãe sofra um novo ataque cardíaco que a levaria à morte, o filho - personagem central da história - busca recriar a extinta Alemanha Oriental, utilizando-se de vários artifícios basicamente visuais.

Esse tema deu margem ao debate sobre a questão política que, em uma determinada época, dividia o mundo entre duas grandes potências: Estados Unidos e União Soviética. 0 filme suscitou a curiosidade acerca de um processo histórico que passou a ser mais conhecido pela maioria dos jovens nessa faixa etária. É o que nos diz Eva:

[...] é bom, porque a gente viu o filme, mas não só viu, foi analisando, sabendo que ia ter uma discussão depois, ia ter um debate, um esclarecimento... dentro do país... O lado positivo da questão da roda de leitura, acredito que foi a questão de discutir os filmes, tanto a forma como o conceito do filme. E também a gente fazer uma exposição de fotos. (grifo dos autores)

Em uma das propostas, os alunos foram 'desafiados' a tirar fotos relacionadas aos filmes que assistiram nas rodas. A exposição dessas fotos teve como foco debates suscitados por esses filmes. Na interpretação das imagens em movimento (cinema) e das imagens fixas (fotos), ficou perceptível a leitura criativa que fizeram.

A realização e exposição de fotos deu margem a determinados questionamentos: "Quais as ideias que teve para a realização das fotos a partir do filme? Como realizou as fotos? Que história contaria dessa foto? Que leitura pode ser feita dela? " A maioria das fotos foi feita registrando os próprios colegas ou mesmo pessoas da família em situações

CC ETD-Educação Temática Digital Campinas, SP $\quad$ v.19 $\quad$ n.2 $\quad$ p. 384-399 abr./jun. 2017 
relacionadas ao filme ou reflexões advindas do debate. Por isso, optamos por não trazer as imagens aqui.

Implicitamente, esses jovens, por vivenciarem uma formação estética e audiovisual, conseguiram inter-relacionar diferentes linguagens. A produção fotográfica possibilitou pensarem nessas e em outras questões, em que associaram os filmes a roteiros baseados em determinados romances. A interpretação do filme, assim como dos textos, provocou os seguintes comentários:

\footnotetext{
Para mim, o cinema é um tipo de leitura, pois um filme sem roteiro fica perdido e confuso. (João)

Os dois - livro e filme - passam uma mensagem para quem lê ou para quem assiste... (Antonia)

Através da leitura muitas vezes sai a ideia de um filme... (Jéssica)

No cinema, temos que fazer a leitura da imagem. (Marina)
}

Viveram, nesse processo, o que Fantin (2006) aponta como dimensão ecológica da mídia-educação, em que se possibilitam diálogos com diferentes linguagens (TV, Internet, fotografia, vídeo, livro etc.) nessa ampliação do olhar sobre o cinema. Fazem e aprendem a fazer a leitura da imagem e, aos poucos, passam a ter uma nova relação com os filmes.

\section{NINGUÉM PERCEBE, MAS VOCÊ VÊ - A ESCOLA COMO MEDIADORA DO VER FILMES}

Nove entre dez dos nossos movimentos obedecem ao hábito e ao automatismo. É contra a natureza subordiná-los à vontade e ao pensamento. Robert Bresson

Uma discussão recorrente nos debates e nas entrevistas com os/as alunos/as do EMI, a partir da entrada na escola (nesse maior convívio com o cinema), foi como mudaram a maneira de olhar os filmes. Antes percebidos de uma forma 'automatizada', sem maiores questionamentos, os filmes passaram a ser vistos a partir da análise da música, do enquadramento, do roteiro, do estilo de cada diretor. Se formos trazer as expressões de Bresson, diríamos que passaram a subordiná-los à vontade e ao pensamento. Algumas das falas podem nos dar ideia de como essa relação com o cinema foi se constituindo nesse espaço escolar:

(C) ETD-Educação Temática Digital Campinas, SP $\quad$ v.19 n.2 $\quad$ p.384-399 abr./jun. 2017 
Aqui, no EMI, nós não aprendemos a ser simplesmente profissionais técnicos, a gente aprendeu também a ser crítico, e muita coisa também... O cinema é um setor, uma ferramenta que dá uma visão... Através do cinema, do documentário, a gente pode mostrar uma situação de humanidade. (João, grifos dos autores)

\section{Perguntamos a João qual o significado de eles passarem a conhecer a técnica de} filmagem:

Eu acho que, principalmente na imagem, você tem que analisar a forma e o conceito. A gente aqui vê mais a forma, pela questão de técnica...Porque a imagem, se você quer mostrar alguém triste, isso depende do plano que você tá mostrando... Se você quer mostrar alguém que é superior, depende do plano que você está colocando... Então, eu acho que também é legal você ler a imagem de uma forma técnica, mas você também tem que ler a imagem de uma forma literal... Com a forma é diferente, porque você vê a questão conceitual... (grifos dos autores)

Essa sensibilidade mais aguçada aponta, segundo eles, para uma mudança no olhar. Essa mudança vai sendo construída na relação que estabelecem com os filmes. Exemplo: o modo de perceber o 'erro' das narrativas fílmicas. Seriam elas associadas à construção que parece ser 'conceitual', como destaca o entrevistado?

Jéssica: - Antes, eu via um filme, não acredito que não só eu, porque todo mundo já chegou a comentar isso, via normal assim, não percebia erro, de nada, sabe, não via nada, aí só pensava na história mesmo do contexto do filme...

Milena: - Se mexeu ou não com você e ponto.

Jéssica: - E não pensava na construção do filme, "pô" depois que eu entrei pra cá, no meu primeiro ano, tudo que eu via, aí ficava pensando nos planos, plano médio, close, não sei o que, não sei o que, vê tudo ...

Milena: - Nos planos de filmagem...

Felipe: - E hoje, a gente abrange tudo quando vê, negócio da iluminação, plano de câmeras, se o roteiro tava bom...

Jéssica: - A atuação...

Felipe: - É, a atuação que o cara fez...

Milena: - Se podia ser melhor...

Jéssica: - Pô... vi um corte errado!

Felipe: - A gente começa a ficar chato, [risos dos participantes] a gente começa a ver tudo do filme...

Vanessa: - Igual à gente quando aprende português...

Entrevistadora: É assim mesmo, você vai gostando e achando interessante... Qualquer errinho... de imagem, de cena, de foco...

Milena: - Ninguém percebe, mas você vê... (grifos dos autores)

\section{(C) ETD-Educação Temática Digital Campinas, SP v.19 n.2 $\quad$ p. 384-399 abr./jun. 2017}


As falas deles demonstram que percebem como essa outra relação com os filmes tem a possibilidade de transformá-los. 'Vendo o que ninguém percebe', eles se formam como audiência que assiste e faz filmes. Em síntese, houve unanimidade no que diz respeito à mudança de postura e ampliação da percepção e análise sobre o significado do cinema. Como aponta Duarte:

[...] as gerações passadas aprenderam a ver filmes, fundamentalmente, em salas de cinema e a conhecer o cinema vendo e discutindo filmes, analisandoos estética e politicamente. Muitas leituras, longas conversas e debates infindáveis eram parte das estratégias de aprendizado empreendidas, voluntariamente, pelos que se definiam como cinéfilos. Nesse contexto, o amor pelo cinema se traduzia numa busca constante de informações sobre a história do cinema e sobre filmes... $(2008$, p.70)

Percebemos que esses jovens estavam vivendo na escola possibilidades que, antes, só existiam fora dela, para os que tinham acesso a essa rede de filmes e debates. Possibilitar esse tipo de experiência na escola é algo que poucos espaços educativos propiciam, razão pela qual a formação estética e audiovisual proporcionada pelo EMI significou, para os jovens da pesquisa - além de entretenimento - uma formação articulada à linguagem dos filmes nesse exercício de análise e reflexão sobre as incorreções de aspectos técnicos e de conteúdos do que assistiram, conforme registrado no depoimento de Antonia:

\footnotetext{
Eu, no primeiro ano, era muito chata, tudo que eu via eu apontava o erro. Depois eu aprendi que erros acontecem. (...) Falam de como a experiência com os filmes, desde o início do ensino médio, revela-se formadora para aqui para poder superar cada um deles e fazer o certo. É com os erros que a gente aprende. E assim... a partir das coisas que foram acontecendo e como iam funcionando, a gente foi ganhando experiência, foi ganhando oportunidade de investir mais, de ajudar mais... Porque aqui a gente trabalha não só como grupo, mas também como uma equipe, quando acontecem erros a gente tá ali pra poder ajudar... Então, esse funcionamento tanto entre a gente como equipe e também essa ligação entre a gente como amigos... Acho que foi uma interação muito legal, e isso influenciou muito, principalmente na minha vida, porque eu aprendi a olhar com o olhar mais crítico, mas não apontando erros, mas sim aprendendo com eles. Para mim é isso... (grifos dos autores)
}

Aprender com os erros, como nos diz Antonia, foi uma das possibilidades que o trabalho com o cinema na escola trouxe para ela. Nesse contexto, os participantes da pesquisa afirmaram que a prática de assistir e debater filmes lhes possibilitou um ganho pessoal importante. Despertou a curiosidade diante de algo novo e aumentou o interesse pelos estudos, além de promover um olhar mais crítico, menos ingênuo, acerca do cinema e

\section{(C) ETD-Educação Temática Digital Campinas, SP v.19 $\quad$ n.2 $\quad$ p.384-399 abr./jun. 2017}


da literatura.

Xavier (2008, p. 15) aponta que ".a dimensão educativa, entendida no sentido da formação (valores, visão de mundo, conhecimento, ampliação de repertório) permeia toda a experiência do cinema e está, ainda que de modo implícito, presente nos debates sobre os filmes." Essa relação com os filmes, como formação, está consubstanciada na observação dos jovens quando explicitam como se dá essa formação para eles na relação com o cinema: "ninguém percebe, mas você vê". Ver para além do que os outros percebem.

\title{
OLHAR EM FORMAÇÃO - CONCLUINDO...
}

\author{
É preciso que uma imagem se transforme no contato com outras \\ imagens, como uma cor no contato com outras cores. \\ Um azul não é o mesmo azul ao lado de um \\ verde, de um amarelo, de um vermelho. \\ Não há arte sem transformação. Robert Bresson
}

As rodas de leitura no EMI apontam, pelas próprias falas dos jovens, seu processo formativo, desde estranhamentos até paixões por aprender a olhar os filmes de outro modo. Provocam transformações no olhar. E, como diz Bresson, na citação anterior, "não há arte sem transformação". Assim, as falas que intitularam os debates anteriores apontam as pequenas transformações, pelas quais os jovens viveram sua relação formativa com o cinema, por acesso a 'filmes diferentes', por 'ver sabendo que iam discutir depois', por só 'reparar [no filme] quem tem aquela prática' e, por fim, por terem aprendizagens aparentemente imperceptíveis para a maioria, pois 'ninguém percebe mas você vê'. Por esses aspectos trazidos pelos jovens já apontam que a relação vivida com o cinema na escola foi uma relação que modificou o olhar deles.

Essa ampliação do olhar deles e o estreitamento de sua relação com os filmes deram margem a possibilidades de leitura antes desconhecidas. Passaram a ter um convívio mais estreito com os filmes e sua leitura, criando maior sociabilidade associada ao cinema e seus possíveis contextos e relações com outras imagens e outros textos. Aprenderam a exercitar o imaginário na leitura de filmes e, no exercício de criação, exploraram filmes e associaram literatura e cinema.

Carrière (1995) comenta que essa aprendizagem com o cinema é cultural e leva tempo. O autor nos leva a pensar como a introdução e o trabalho com o cinema trazem

\section{(C) ETD-Educação Temática Digital Campinas, SP v.19 n.2 p.384-399 abr./jun. 2017}


inúmeros desafios que dependem do contexto cultural. Traz uma situação vivida em terras distantes, mas que pode nos ajudar a pensar no vivido na escola:

\begin{abstract}
Naquelas mesmas terras africanas, nos primórdios do cinema, quando os espectadores menos intransigentes abriam realmente os olhos para o novo espetáculo, mal podiam compreendê-lo. Mesmo quando reconheciam algumas das imagens em outro lugar - um carro, um homem, uma mulher, um cavalo -, não chegavam a associá-las entre si. A ação e a história os deixavam confusos. Com uma cultura baseada em rica e vigorosa tradição oral, não conseguiam se adaptar àquela sucessão de imagens silenciosas, o oposto absoluto daquilo a que estavam acostumados. Ficavam atordoados. Ao lado da tela, durante todo o filme, tinha que permanecer um homem, para explicar o que acontecia. [...] Era o chamado explicador. (p. 13)
\end{abstract}

Nesse processo, de maior convívio com o cinema, esses jovens passaram a integrá-lo em suas experiências de vida, o que contribuiu para formação de cada um deles. A escola, cumprindo o papel de mediadora, possibilitou, pelas exibições, debates e produções, um aprendizado que ampliou o ver além de um olhar automatizado e, por vezes, banalizado, de grande parte dos espectadores. Passaram a ser 'os explicadores' para os demais, para os que não tinham aquela prática e não pertenciam a essa comunidade de leitores. Passaram a ser 'explicadores' para a família e colegas de fora da escola. A escola se tornou referência como espaço para ler e analisar filmes.

Como discute Dussel (2014), a pesquisa com cinema na escola reforça a ideia de que, nem sempre, as experiências com o cinema precisam resistir a serem escolarizadas devido à crítica de que a adaptação escolar perderia o que o cinema tem de valioso: a capacidade de permitir uma experiência estética rica e imprevisível. A autora se propõe a problematizar a questão, mostrando que a tradução escolar não é necessariamente empobrecedora, o cinema pode ser uma experiência que abre mundos novos de sensibilidade e alteridade na escola. A autora faz essas problematizações, trazendo resultados de pesquisas recentes realizadas na Argentina e no México, em que foi possível perceber mudanças importantes na relação dos estudantes e professores com o cinema e as tecnologias visuais. Essas mudanças, percebidas por Dussel em suas pesquisas e também trazidas por nós na pesquisa aqui relatada, trazem desafios importantes, mostrando que o cinema pode abrir outros mundos de experiência dentro e fora da escola, e que a escola pode ser, sim, um espaço de mediação e formação importante.

\title{
(C) ETD-Educação Temática Digital Campinas, SP v.19 $\quad$ n.2 $\quad$ p. 384-399 abr./jun. 2017
}


DOI: $\underline{\text { https://doi.org/10.20396/etd.v19i2.8647625 }}$

\section{REFERÊNCIAS}

BRESSON, Robert. Notas sobre o cinematógrafo. São Paulo, SP: Iluminuras, 2005.

CABRERA, Julio. O cinema pensa: uma introdução à filosofia através dos filmes. Rio de Janeiro, RJ: Rocco, 2006.

CARRIÉRE, Jean-Claude. A linguagem secreta do cinema. Rio de Janeiro, RJ: Nova Fronteira, 1995.

CORDEIRO, Kelly Maia. Cinema e juventude: relações criadas pelos jovens dentro e fora da escola. Dissertação (Mestrado em Educação) - Programa de Pós-graduação em Educação, Universidade Federal do Estado do Rio de Janeiro. Rio de Janeiro, RJ, 2012.

DUARTE, Rosália; ALEGRIA, João. Formação estética e audiovisual: um outro olhar para o cinema a partir da educação. Revista Educação e Realidade, v. 33, n. 1, p.59-79, 2008. Disponível em: http://seer.ufrgs.br/index.php/educacaoerealidade/article/view/6687/4000 Acesso em: agosto de 2016.

DUSSEL, Ines. Usos del cine em la escuela: uma experiência atravessada por la visualidad. Revista Estudos da Lingua(gem), v.12, n. 1, p.77-100, junho de 2014. Disponível em: http://www.estudosdalinguagem.org/index.php/estudosdalinguagem/article/viewFile/413/ $\underline{372}$ Acesso em: agosto de 2016.

FANTIN, Monica. Mídia-educação, cinema e produção audiovisual na escola. IN: VI ENCONTRO DOS NUCLEOS DE PESQUISA DA INTERCOM, 6. São Paulo, SP. 6 a 9 de setembro. Anais... Brasília, DF: UNB, 2006. Disponível em: http://www.intercom.org.br/papers/nacionais/2006/resumos/r0652-1.pdf Acesso em: agosto de 2016.

FERNANDES, Adriana Hoffmann; SILVA, Andreia Cristina Attanazio. Consumo cultural e produção de sentidos: o papel da comunidade interpretativa. In: CONGRESSO INTERNACIONAL COTIDIANO: DIÁLOGOS SOBRE DIÁLOGOS, Rio de Janeiro, RJ, 2005. Anais eletrônicos..., 1CD-ROM. Rio de Janeiro, RJ: UFF, 2005.

FERNANDES, Adriana Hoffmann. O cinema e a narrativa de crianças e jovens em diferentes contextos educativos. Projeto de pesquisa - Universidade Federal do Estado do Rio de Janeiro, FAPERJ. Rio de Janeiro, RJ, 2010. 
FERNANDES, Adriana Hoffmann. As crianças e os desenhos animados: mediações nas produções de sentido. Rio de Janeiro, RJ: Nau, 2012.

GARCIA, Pedro Benjamim. Literatura e identidade: tecendo narrativas em rodas de leitura. In: DAUSTER, Tania; FERREIRA, Lucelena (Org.). (2010). Por que ler? Rio de Janeiro, RJ: Lamparina/FAPERJ, p.79, 2010.

GARCIA, Pedro Benjamim. Formação do leitor com imagens e textos em rodas de leitura. Projeto de pesquisa - Universidade Católica de Petrópolis; CNPq. Rio de Janeiro, RJ, 2010.

MACHADO, Arlindo. Pré-cinemas e pós-cinemas. Campinas, SP: Papirus, 2007.

SAVERNINI, Erika. Índices de um Cinema de poesia: Pier Paolo Pasolini, Luis Buñuel e Krzysztof Kieslowski. Belo Horizonte, MG: UFMG, 2004.

SERRA, Maria Silvia. El cine em La escuela. Política a pedagogia de la mirada? IN: DUSSEL, Ines; GUTIERREZ, Daniela. Educar la mirada: políticas y pedagogias de la imagen. Buenos Aires: FACSO, OSDE, p. 55-66, 2006.

VARELA, Mirta. De las culturas populares a las comunidades interpretativas: fragmentación e consenso en el campo de comunicación y cultura. Revista Diálogos de la Comunicación, São Paulo, SP. n.56, out-1999. Disponível em:

http://www.periodismo.uchile.cl/talleres/teoriacomunicacion/archivos/varela.pdf Acesso em: agosto de 2016.

XAVIER, Ismail. Um cinema que "educa" é um cinema que (nos) faz pensar. Revista Educação e Realidade, v. 33, n. 1, p. 13-20, 2008. Disponível em: http://seer.ufrgs.br/index.php/educacaoerealidade/article/view/6683/3996 Acesso em: agosto de 2016.

\footnotetext{
' Revisão gramatical do texto sob a responsabilidade da equipe da revista ETD
} 